\title{
REVIEW
}

\section{The year in cardiology: aorta and peripheral circulation}

Christian Heiss ${ }^{1,2}$, Alex Pitcher ${ }^{3}$, Jill J.F. Belch ${ }^{4}$, Marco De Carlo5, Holger Reinecke ${ }^{6}$, Iris Baumgartner ${ }^{7}$, Lucia Mazzolai ${ }^{8}$, and Victor Aboyans ${ }^{9,10}$; on behalf of the ESCWorking Group on Aorta and Peripheral Vascular Diseases

\section{PREAMBLE}

Similar to previous years, ${ }^{1-3}$ the current article reviews groundbreaking science published 2019 in the area of aortic and peripheral arterial diseases (PAD) as well as venous thromboembolic disease (VTE) that will affect our daily clinical practice. With the growing recognition of PAD, it will be necessary to consolidate imprecisions in terminology. Many are used to the acronym PAD for atherosclerotic disease of the lower extremity arteries. Others have used the same acronym to qualify atherosclerotic disease of the lower extremity arteries and carotid arteries. In the current article and in line with the European Society of Cardiology (ESC) guidelines, ${ }^{4}$ we have stringently used the specific terms lower extremity arterial disease (LEAD) and reserved PAD as the umbrella term encompassing all arterial diseases other than aorta and coronaries.

\footnotetext{
' Department of Clinical and Experimental Medicine, University of Surrey, Stag Hill I4AY04, Guildford GU2 7XH, UK

${ }^{2}$ Surrey and Sussex Healthcare NHS Trust, East Surrey Hospital, Canada Avenue, Redhill RHI 5RH, UK

${ }^{3}$ Division of Cardiovascular Medicine, Radcliffe Department of Medicine, University of Oxford, John Radcliffe Hospital, Headington, Oxford OX3 9DU, UK

${ }^{4}$ The Institute of Cardiovascular Research, University of Dundee, Ninewells Hospital and Medical School, Ninewells Hospital, Dundee DDI 9SY, UK

${ }^{5}$ Cardiac Catheterization Laboratory, Cardiothoracic and Vascular Department, Azienda Ospedaliero-Universitaria Pisana, via Paradisa 2, 56100 Pisa, Italy

${ }^{6}$ Department of Cardiology I-Coronary and Peripheral Vascular Disease, Heart Failure, University Hospital Muenster, Albert Schweitzer Campus I, AI, 48I49 Muenster, Germany

${ }^{7}$ Clinical and Interventional Angiology, Swiss Cardiovascular Center Bern, Insel Group AG, University Hospital Bern, Freiburgstrasse 18, 3010 Bern, Switzerland

${ }^{8}$ Division of Angiology, Department of Heart and Vessel, Lausanne University Hospital, Ch du Mont-Paisible 18, Lausanne 10II, Switzerland

9 Department of Cardiology, Dupuytren University Hospital, 2, Martin Luther King Ave., 87042 Limoges, France

${ }^{10}$ Inserm 1094, Limoges School of Medicine, Ave Dr. Marcland, 87025 Limoges, France
}

\section{VASCULAR BIOLOGYI TRANSLATIONAL RESEARCH}

The extent to which genetic factors contribute to PAD development and if they are shared or distinct between LEAD, cerebral, and coronary arteries are largely unknown. In a genome-wide association study in the Million Veteran Program, 32 million DNA sequence variants were tested for PAD (3I $307 \mathrm{ca}-$ ses, 211753 controls) and combined with electronic health records. ${ }^{5}$ The results were replicated in an independent sample from the UK Biobank. They identified I 9 LEAD loci ( 8 not previously reported): I I loci were associated with disease in three vascular beds (coronary, cerebral, and lower extremity), including LDLR, LPL, and LP(a) (Take home figure); 4 loci appeared to be specific for LEAD, including F5 p.R506Q (Factor $V$ Leiden variant), highlighting the pathogenic

\footnotetext{
Contact address:

Christian Heiss

Department of Clinical and Experimental Medicine, University of Surrey, UK

Surrey and Sussex Healthcare NHS Trust, East Surrey Hospital, Canada Avenue, UK

E-mail: c.heiss@surrey.ac.uk (C.H.); Tel: +44 (0) 78785898I7

E-mail:vaboyans@live.fr (V.A); Tel: +33 555056 310,

Fax: +33 555056364

\section{Copyright:}

Christian Heiss, Alex Pitcher, Jill J F Belch, Marco De Carlo, Holger Reinecke, Iris Baumgartner, Lucia Mazzolai, Victor Aboyans, on behalf of the ESC Working Group on Aorta and Peripheral Vascular Diseases, The year in cardiology: aorta and peripheral circulation: The year in cardiology 2019,European Heart Journal, Volume 4I, Issue 4, 21 January 2020, Pages 50I-508b,https://doi.org/I0.1093/eurheartj/ehz939 Published on behalf of the European Society of Cardiology. All rights reserved.

For permissions, please email: journals.permissions@oup.com
} 


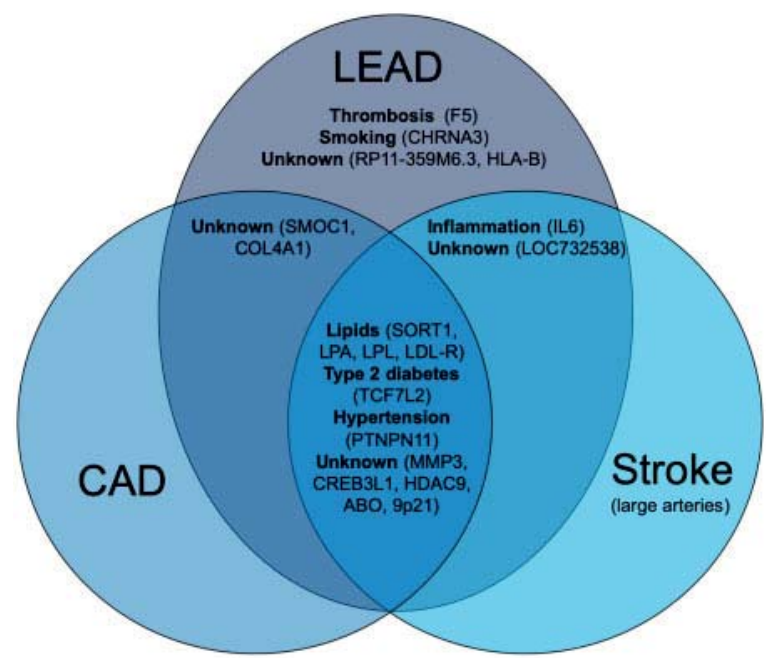

Take home figure. Lower extremity artery disease (LEAD) risk variants and mechanistic overlap with coronary artery disease (CAD) and large artery stroke. Venn diagram of each of the 19 LEAD risk loci in a based on their association with LEAD ( $N=31307$ LEAD cases and 21 I 753 controls), CAD ( $N=1$ I I 216 CAD cases and 248 08I LEAD controls), and large artery stroke ( $N=7393$ large artery stroke cases and 628737 controls) using logistic regression. Each locus is stated next to the plausible relationship with the underling risk factor and the loci names are based on the nearest genes. Figure adapted from Ref. ${ }^{5}$

role of thrombosis in LEAD and supporting Factor Xa inhibition as a therapeutic strategy.

Despite the fact that numerous long non-coding RNAs (IncRNA) have been identified, only a few of them have been studied with respect to endothelial cell homeostasis or vascular disease development. One of them, the pro-angiogenic IncRNA MANTIS, may be clinically relevant in carotid disease. ${ }^{6}$ In fact, the protective effects of laminar flow and statins are, at least in part, attributed to the expression of MANTIS. The mechanisms involve epigenetic rearrangements and the transcription factors Krüppel-like factor 2 and 4. As induction of MANTIS mimics the beneficial effects of statins on endothelial function, the authors proposed that strategies to increase MANTIS might improve vascular function in patients not responding to statin therapy.

The transcriptional activity of nuclear receptors that regulate key pathophysiological processes in atherosclerosis development is controlled by the nuclear receptor corepressors (NCOR), scaffolding proteins that form the basis of large corepressor complexes. Oppi et al. ${ }^{7}$ investigated the role of NCORI in atherogenesis. Myeloid cellspecific deletion of NCORI in LDL receptor knockout mice aggravated atherosclerosis development. Macrophage NCORI- deficiency led to increased foam cell formation, enhanced expression of pro-inflammatory cytokines, and atherosclerotic lesions characterized by larger necrotic cores and thinner fibrous caps. The immunometabolic effects of NCORI were mediated via suppression of peroxisome proliferator-activated receptor gamma (PPARc) target genes in mouse and human macrophages, which lead to an enhanced expression of the CD36 scavenger receptor and subsequent increase in oxidized LDL uptake in the absence of NCORI. Interestingly, in human atherosclerotic plaques, the expression of NCORI was reduced, whereas the PPARc signature was increased, and this signature was more pronounced in ruptured compared with nonruptured carotid plaques. The data suggest that stabilizing the NCORIPPARc binding could be a promising strategy to block the pro-atherogenic functions of plaque macrophages and lesion progression.

Radiotherapy-induced cardiovascular disease (CVD)is an emerging problem in a growing population of cancer survivors where traditional vascular treatments have limited benefits. Using a translational approach, it was now shown that human irradiated blood vessels exhibit elevated levels of inflammation signals associated with inflammasome activation long after radiotherapy, and similar changes occurred in 
a mouse model of localized irradiation to the heart and carotids. ${ }^{8}$ In the model, the localized inflammatory response was ameliorated by an interleukin (IL)- I receptor antagonist. Clinical studies in humans now need to evaluate IL-I blockade as a potential treatment of radiotherapy-induced CVD.

Subjects with Lp(a) elevation have increased arterial wall inflammation and cardiovascular risk. Stiekema et al. ${ }^{9}$ evaluated whether evolocumab, which as opposed to statins lowers both LDL-cholesterol and Lp(a), attenuates arterial wall inflammation in the index vessel (carotid or thoracic aorta) in patients with elevated Lp(a) (>200 mg/dL). In this multicentre, randomized, double-blind, placebo-controlled study, 129 patients were randomized to monthly subcutaneous evolocumab $420 \mathrm{mg}$ or placebo. Compared with placebo, evolocumab reduced LDL-cholesterol by $60.7 \%$ [95\% confidence interval $(\mathrm{Cl})$ 65.8-55.5] and $\mathrm{Lp}(\mathrm{a})$ by only $13.8 \%(95 \% \mathrm{Cl} 19.3-8.5)$. Importantly, arterial wall inflammation [assessed by [(positron emission tomography with 2- deoxy-2-[fluorine- I8]-fluoro-D-glucose integrated with computed tomography)] I8F-FDG $\mathrm{PET} / \mathrm{CT}]$ was not significantly altered with evolocumab at Week 16. This supports that, beyond economic issues, statins remain the first pillar of lipid-lowering therapies, which ties in with current lipid guidelines. ${ }^{10}$

Another large study characterized serum metabolic signatures associated with atherosclerosis in the carotid and coronary arteries and subsequently their association with incident CVD among 3867 participants from the Multi-Ethnic Study of Atherosclerosis (MESA), with replication among 3569 participants from the Rotterdam and LOLIPOP studies." They showed that $30 \mathrm{IH} \mathrm{NMR} \mathrm{(proton} \mathrm{nuclear} \mathrm{magnetic}$ resonance spectroscopy) measured metabolites were associated with coronary artery calcium and/or carotid intima-media thickness. Metabolites associated with atherosclerosis were largely consistent between the carotid and coronary vascular beds and predominantly tag pathways that overlap with the known cardiovascular risk factors: disturbances in lipid and carbohydrate metabolism, branched chain, and aromatic amino acid metabolism, as well as oxidative stress and inflammatory pathways.

\section{VASCULAR BIOMARKERS AND CARDIOVASCULAR RISK}

Multimodality vascular assessment enables to evaluate the atherosclerotic process and the cardiovascular risk. In a population-based study ${ }^{12}$ using hybrid
I8F-FDG PET and magnetic resonance imaging (MRI), arterial inflammation was detected in $48 \%$ of participants of $40-54$ years of age, increasing steadily by the number of risk factors. Aortic, carotid, and/or iliofemoral plaques were present in $90 \%$ of cases, but most inflammation was depicted in the plaque-free zones. Inflammation was present only in I I\% of plaques, suggesting arterial inflammation in early stage of atherosclerosis process. An experimental study went one step further and developed a integrative multiparametric $\mathrm{PET} / \mathrm{MRI}$ protocol that allows non-invasive assessment of different processes relevant to atherosclerosis progression. ${ }^{13}$ Using clinically approved nanobody radiotracers, they were able to study different biomarkers of atherosclerosis progression, namely vascular cell adhesion molecule-I, lectin-like oxidized low-density lipoprotein receptor-I, and macrophage mannose receptor, that correlated with histopathological findings in mice and rabbits.

Atherosclerosis is even identifiable in adolescence, especially in case of unhealthy lifestyle: in an observational study ${ }^{14}$ including 1266 young participants aged 13-I7 years, aortic stiffness, estimated by carotid-femoral pulse-wave velocity (cfPWV) was proportionally increased by the tobacco smoking and alcohol drinking intensities, with a strong potentiation when both were combined (Figure I). At these ages, smoking and drinking cessation lead to normalization of cfPWV. In the other lifespan tip, vascular markers could be useful to downgrade the estimated risk in elderly people who would have an indication for statins based on risk scores, highly affected by age. In a cohort of 5805 healthy elderly participants (mean age 69 years), normal $(<10)$ coronary calcium score and no carotid plaque on ultrasound were the most powerful vascular markers to downgrade the predicted cardiovascular risk, with respective net reclassification index of 0.29 and 0.14 , avoiding unnecessary statin prescription in $34 \%$ and $21 \%$ of cases. ${ }^{15}$

Ultrasound vascular imaging can efficiently improve patients' adherence to medical advice for healthy lifestyle. The Visualization of asymptomatic atherosclerotic disease for optimum cardiovascular prevention (VIPVIZA) open controlled trial ${ }^{16}$ randomized 3532 individuals $>40$ years attending a screening programme; the control group received regular risk factors screening and guidelines-based management but the results of carotid ultrasound were not disclosed, while the intervention group received, along with their general practitioners, a pictorial presentation of the carotid 
A

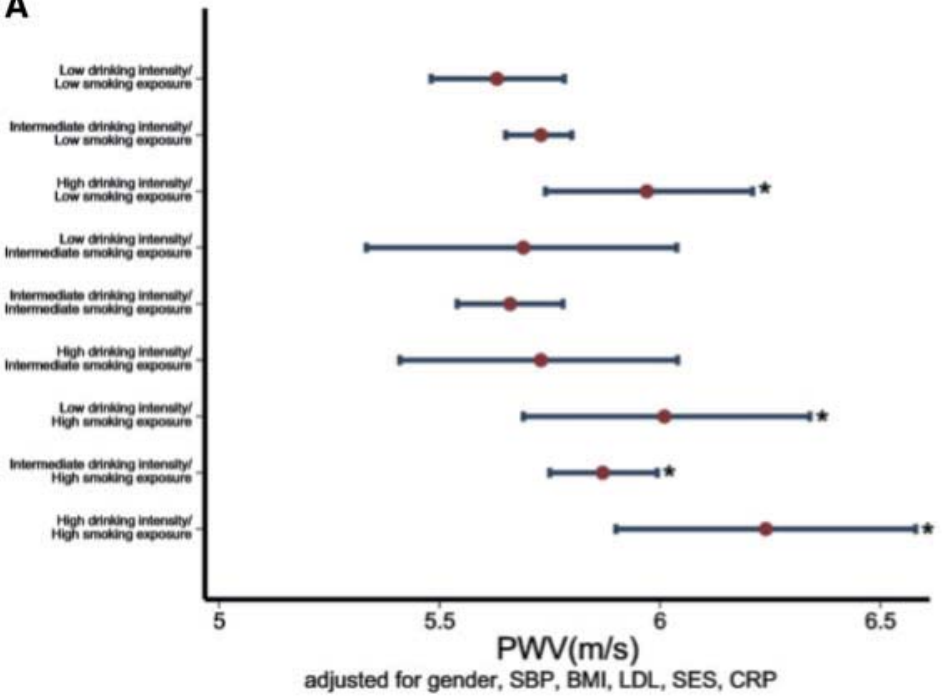

B
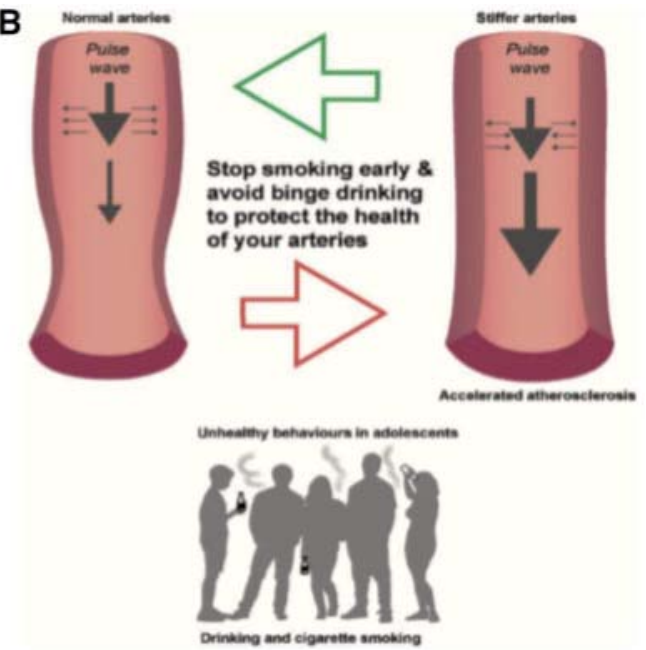

Figure I. (A) The combined effect of smoking over lifetime and intensity of drinking on arterial stiffness. The combination of high-intensity drinking with lifetime smoking exposure is shown. Pulse wave velocity measurements are expressed as mean values and $95 \%$ confidences intervals around the mean on the $\mathrm{x}$-axis. The participants who had 'high' drinking intensity and 'high' smoking exposure had the highest pulse wave velocity compared with the 'low lifetime smoking exposure' and 'low drinking intensity'. ${ }^{\mathrm{P}}<0.05$. (B) Unhealthy behaviours in adolescents (drinking and cigarette smoking) are associated with increased carotid to femoral pulse wave velocity (stiffer arteries) and accelerated atherosclerosis. Stopping smoking in adolescents and reducing binge drinking has potential for reversibility of arterial stiffening. Reproduced with permission fromRef. ${ }^{14}$

ultrasound results, including colour-scaled presentations of vascular age based on intima-media thickness, and plaque identification. A nurse called 2-4 weeks later to reassure participants and provide any information needed. The same pictorial information was repeated after 6 months. The baseline Framingham risk score (FRS) and SCORE were respectively at 12.9 and I.28. At I year, both scores were significantly lower in the intervention group $(-1.07, P=0.0017$ for FRS and $-0.16, P=0.001$ for SCORE), with more striking results in the high-risk group $(-2.16$ and -2.85 , respectively). The persistence of these results and their consequences on CVD events need further evaluation.

\section{CEREBROVASCULAR DISEASE}

Excessive arterial pulsatility may contribute to cognitive decline and risk of dementia via damage to the fragile cerebral microcirculation. As part of the Whitehall II study, ${ }^{17}$ peak forward-travelling compression wave intensity (FCWI) was assessed using Duplex ultrasound within the common carotid arteries in 3191 individuals (mean age $=61$ years; $75 \%$ male) and serial measures of cognitive function were taken at baseline and almost 10 years later. Higher FCWI at baseline was associated with accelerated cognitive decline during follow-up and this association was largely driven by cognitive changes in individuals with the highest FCWI. Compared to other participants, this group was approximately $50 \%$ more likely to exhibit cognitive decline, even after adjustments for multiple potential confounding factors.

While intensive lipid lowering is recommended after transient ischemic attack (TIA) and ischaemic stroke the target level for LDL to reduce cardiovascular events after stroke has not been well studied. In a parallel group trial, 2860 patients with recent ischaemic stroke or TIA and evidence for cerebrovascular and coronary artery atherosclerosis were randomized to either LDL target of $<70 \mathrm{mg} / \mathrm{dL}$ or $90-110 \mathrm{mg} / \mathrm{dL}$ with a statin, ezetimibe, or both. ${ }^{18}$ During a mean followup of 3.5 years, major cardiovascular events occurred less in the lower target group [8.5\% vs. $10.9 \%$; hazard ratio (HR) $0.78(95 \% \mathrm{Cl} 0.6 \mathrm{I}-0.98)]$.

Patients with high stroke risk and atrial fibrillation who are unsuitable for oral anticoagulants (OACs) require alternative stroke prevention strategies. The multicentre, non-randomized, first-in-human clinical Carotid Artery Implant for Trapping Upstream Emboli for Preventing Stroke in Atrial Fibrillation Patients (CAPTURE) trial sought to determine the feasibility 
A

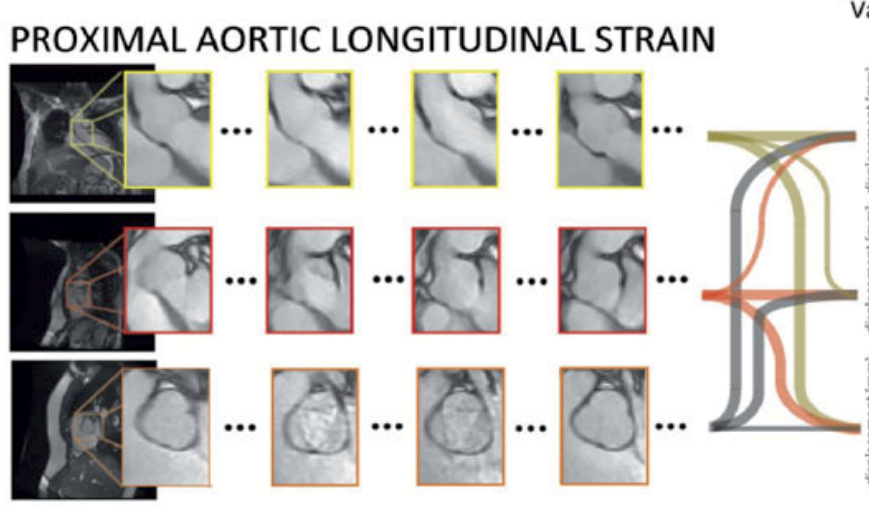

Valve movement in the patient's axis

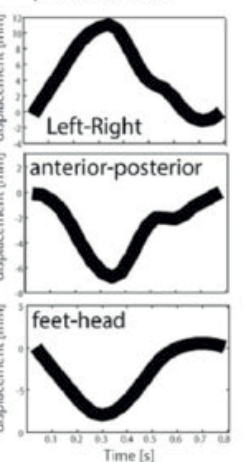

3D aortic valve movement projection into AAo direction

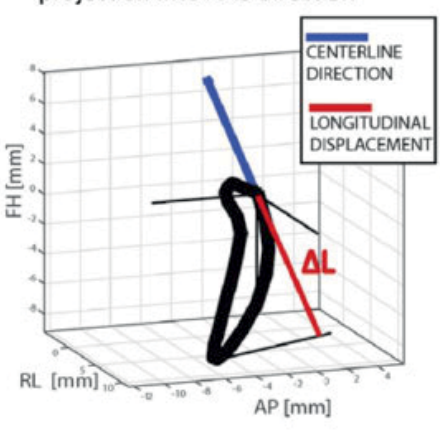

B
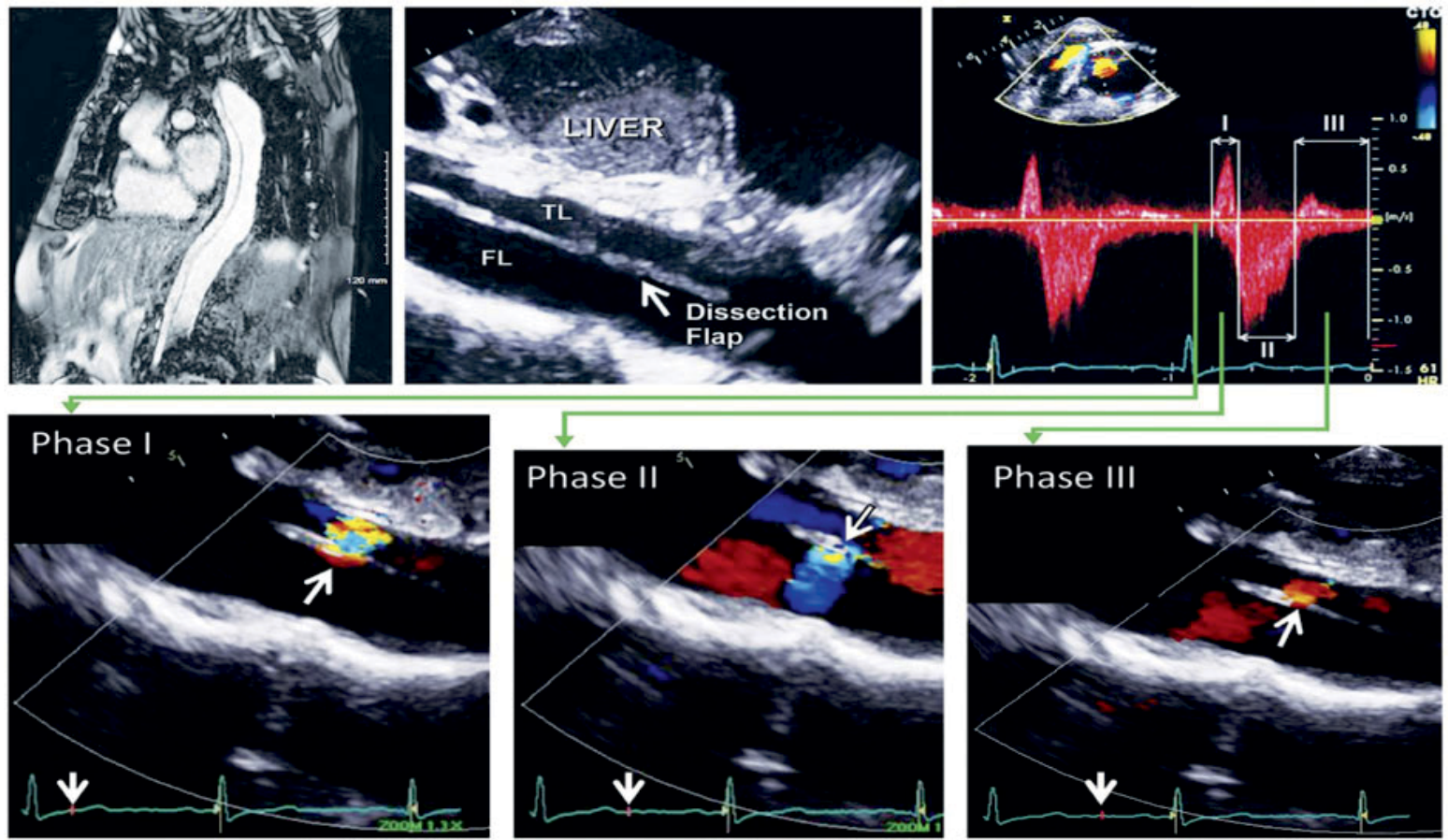

Figure 2. New imaging techniques for risk stratification in patients with aortic diseases (A) methods for proximal longitudinal strain measurement by magnetic resonance imaging, ${ }^{23}$ (B) Doppler approach to flow in aortic dissection. Reproduced with permission from Ref. ${ }^{24}$

and safety of a novel permanent coil filter directly placed into both common carotid arteries designed to capture emboli $>1.4 \mathrm{~mm}$ in diameter. ${ }^{19}$ Patients received aspirin/clopidogrel for 3 months, and aspirin thereafter. In three centres, 25 patients with atrial fibrillation, with CHA2DS2-VASc $\geq 2$, who were unsuitable for OACs and had no carotid stenosis $>30 \%$ were enrolled. The procedure success was $92 \%$; I patient had unilateral deployment. There were no device/procedure-related major adverse events. After 6-month mean follow-up, asymptomatic thrombi were detected in four patients (one bilateral, four unilateral) and the thrombi dissolved with subcutaneous heparin. Permanent carotid filter placement for stroke prophylaxis seems technically feasible and safe. Larger studies and a comparison with the use of left atrial appendage occluders are necessary.

\section{AORTIC DISEASE}

A common challenge in the emergency room is to distinguish patients with symptoms suggestive of acute aortic syndrome (AAS) requiring a computed tomography scan, from others. In a study of 839 patients attending the emergency room with suspected AAS, focused cardiac ultrasound, integrated into a strategy including clinical assessment and (for low-risk patients) D-Dimer testing, enabled the correct identification of all patients with aortic dissection (AD), although the upper border of the $95 \% \mathrm{Cl}$ was $1.2 \% .{ }^{20}$ These findings confirm the importance of transthoracic chocardio- 
graphy in the diagnostic strategy of AAS as suggested in the last ESC guidelines. ${ }^{21}$

The term AAS has become commonplace, but constitutes a range of disease entities, which may not have the same pathophysiological mechanisms, responses to treatment or outlook. Among 1012 patients, those with intra-mural haematoma $(\mathrm{IMH})(\mathrm{n}=340)$ had a much better short- and long-term mortality than those patients with $A D(n=672) .{ }^{22}$ Taking the Type B IMH in-hospital mortality, estimated at $1.5 \%$, as reference, the overall crude in-hospital mortality of Type A AD was $15.0 \%$ with an adjusted hazard ratio (aHR) of 30.4 ; compared to Type A IMH mortality of 8.0\% (aHR 4.85) and Type B ADmortality of 5.0\% (aHR 3.5I).

Identifying patients with Marfan syndrome at particular risk of $A D$ is currently based on the absolute diameter of the aorta, the growth rate, and the presence/absence of a family history of AD. A novel additional approach may be the evaluation of the longitudinal strain of the proximal aorta by MRI (Figure 2A). ${ }^{23}$ Higher strain rates were associated with more rapid aortic expansion and appeared to predict clinical outcomes. If proximal aortic strain is reproducible and if these findings are replicated in larger cohorts, this may help to inform the need for, and timing of, surgery in these patients.

Complex flow patterns are identified in the true and often the false lumen after $A D$. A better understanding of these flow dynamics may explain the differing behaviour of ADs over the long term. Recent insights into this process have become available from detailed study categorizing flow patterns using echo Doppler. The potential for prognostic implications is discussed (Figure 2B). ${ }^{24}$

The optimal management of descending thoracic aortic aneurysms is controversial. A retrospective study on a propensity-adjusted population of Medicare beneficiaries found lower perioperative and overall mortality in patients undergoing thoracic endovascular aortic repair (TEVAR) compared to open repair, but with a higher risk of reintervention. ${ }^{25}$ The odds of perioperative mortality were greater for open surgical repair and depended on the centre volume: highvolume centre, odds ratio (OR) I.97 (95\% Cl I.5-2.6); low-volume centre, OR 3.62 (95\% Cl 2.9-4.5). The restricted mean survival time difference favoured TEVAR at 9 years, -209 days ( $95 \% \mathrm{Cl}-299$ to -120 days) for open surgical repair. The risk of reintervention was lower for open surgical repair, HR $0.40(95 \% \mathrm{Cl}$ 0.34-0.60).
In the last ESC guidelines on the management of aortic diseases, ${ }^{21}$ both open surgery and endovascular aneurysm repair (EVAR) of abdominal aneurysms received Class I recommendation, based on several head-to-head trials enrolling patients with suitable anatomy for both options. While, in the short term, EVAR was associated with lower mortality, this difference was gradually annihilated over time, while in turn, EVAR requested repeated $\mathrm{X}$-ray exposure and reinterventions for endoleaks. The results of very long-term follow-up (I4 years) of the Open vs. Endovascular Repair (OVER) trial ${ }^{26}$ are interesting in that they show no mortality or secondary procedure difference beyond the first years. These results support current recommendations; importantly, mortality was largely not aneurysmrelated (only $2.7 \%$, mostly postoperative), and mostly due to cardiovascular causes, emphasizing the need for maximal preventive measures in these patients. Finally, gender-specific evidence is still lacking, as women constituted $<10 \%$ of all participants.

\section{LOWER EXTREMITY ARTERY DISEASE}

Lower extremity arterial disease is an increasing public health problem according to the latest global epidemiology report. ${ }^{27}$ In 2010, LEAD, defined as $A B I \leq 0.9$, affected 202 million subjects worldwide; this number increased by $22 \%$ to 237 million in 2015 . The overall prevalence in subjects aged $\geq 25$ years was $5.6 \%(95 \%$ $\mathrm{Cl}$ 3.8-8.6), higher in high-income countries than in low- and middle-income countries (LMIC) $(7.4 \%$ vs. $5.1 \%)$, although the vast majority of patients (73\%) lived in LMIC. This prevalence was similar between sexes, with higher rates of young $(<50$ years) patients in LMIC.

The association of LEAD with major adverse cardiovascular events (MACE) is well documented, whereas its association with limb events is less clear. In the Veterans Aging Cohort Study, including 125674 subjects without history of prior amputation, the incidence of amputation over a median of 9.3 years of followup was 1.2 per 1000 person-years..$^{28}$ The presence of LEAD conferred a 13.9-fold increase in amputation risk, but microvascular disease (MVD), defined as retino-, neuro-, and/or nephropathy, was also associated with a 3.7-fold risk increase, and the combination of LEAD and MVD lead to a 22.7-fold increased risk. Importantly, MVD alone was associated with $15 \%$ of all below-the-knee amputations. 


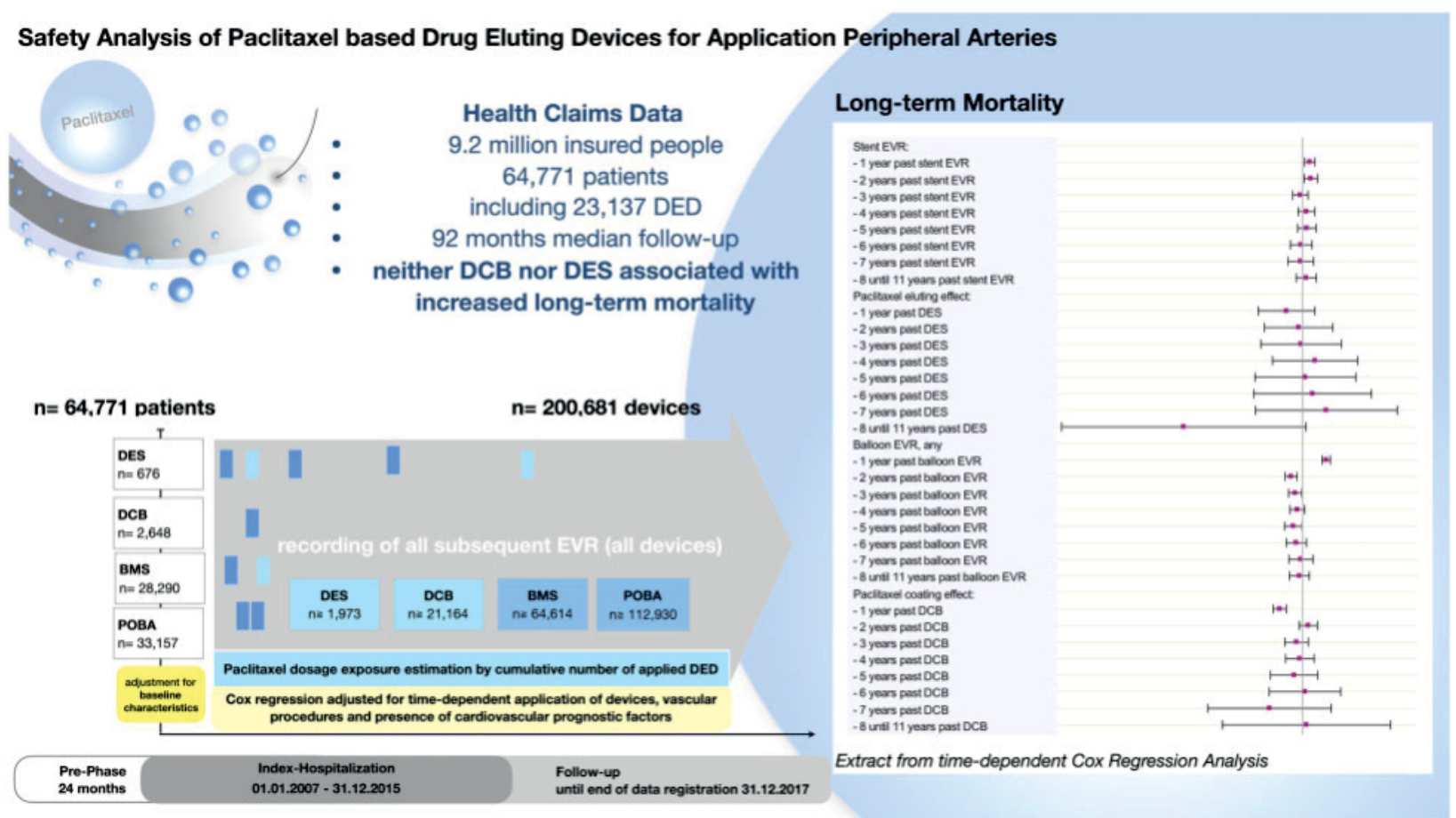

Figure 3. Long-term mortality after use of paclitaxel-based drug eluting devices (DED) in lower extremity arterial disease.A multivariable Cox regression analysis was developed including numerous comorbidities and all devices that were applied in each treated patient. For each distinct device, the analysis accounted for its type [drug-eluting stents (DES), drug-coated balloon (DCB), bare metal stents (BMS), and plain old balloon angioplasty (POBA)] and application date. The model took also concern of any non-constant time dependent effects: thus, a potentially detrimental effect of DED in the later course of time would become verifiable despite a potentially beneficial effect in the early years, or also any potential aggregation of subsequently applied devices. Combined hazard ratios for any scenario including multiple devices that were applied various years ago can be determined as the product of elementary hazard ratios. In summary, there was no signal that paclitaxel DCBs orDESs were associated with increasedmortality up to II years of follow-up. Reproduced with permission from Ref. ${ }^{40}$

Among the 13885 patients with an $A B I \leq 0.8$ or prior lower extremity revascularization (LER) randomized to ticagrelor vs. clopidogrel in the Examining Use of Ticagrelor in Peripheral Artery Disease (EUCLID) trial, the rate of acute limb ischaemia (ALI) requiring hospitalization was 0.8 per 100 patient-years, with no difference between treatment arms. ${ }^{29}$ Acute limb ischaemia was strongly associated with subsequent MACE (aHR I.4, 95\% Cl I.0-2.I), all-cause mortality (aHR 3.3, 95\% Cl 2.4-4.6), and major amputation (aHR 34.2, 95\% Cl 9.7-20.8). Previous LER, baseline atrial fibrillation, and baseline $A B I \leq 0.60$ were independent predictors of ALI. In this trial, a second analysis showed that $12.5 \%$ of patients experienced LER during the trial. ${ }^{30}$ Independent predictors of postrandomization LER were prior history and type of prior LER $(P<0.000 I)$, living in North America or Europe $(P<0.000 \mathrm{I})$, presence of limb symptoms at baseline (HR I.3; 95\% CI I.2-I.5), diabetes (HR I.3; 95\%

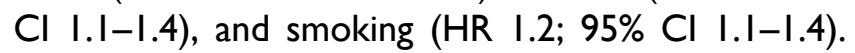
Cardiac and limb events were numerically higher in patients undergoing surgical procedures, but surgical patients experienced fewer LERs after the index LER.
A growing proportion of ALI hospitalizations occurs in cancer patients who experience arterial thromboembolism. In the population-based Surveillance Epidemiology and End Results-Medicare linked dataset, 37433 I patients $\geq 67$ years with primary diagnosis of breast, lung, prostate, colorectal, bladder, uterine, pancreatic, gastric cancer, or non-Hodgkin lymphoma were identified. ${ }^{31}$ The risk of arterial thromboembolic events began to increase 150 days before the date of cancer diagnosis in older patients and peaked in the 30 days before cancer diagnosis, when $0.62 \%$ of patients suffered an arterial thromboembolic event vs. $0.11 \%$ in control subjects (OR 5.63; 95\% Cl 5.07-6.25).

Lipid lowering is a key element of LEAD treatment. ${ }^{4}$ The 2019 ESC guidelines recommend a LDL-cholesterol reduction of $\geq 50 \%$ and a goal of $<55 \mathrm{mg} / \mathrm{dL}$ $(1.4 \mathrm{mmol} / \mathrm{L})$ for LEAD patients, to be achieved with statins, plus ezetimibe and PCSK9 inhibitors if needed. ${ }^{10} \mathrm{~A}$ recent pre-specified analysis of the Evaluation of CV Outcomes After an Acute Coronary Syndrome During Treatment With Alirocumab (ODYSSEY OUTCOMES) trial further supports these recommendations. ${ }^{32}$ After a median follow-up of 2.8 years, the 


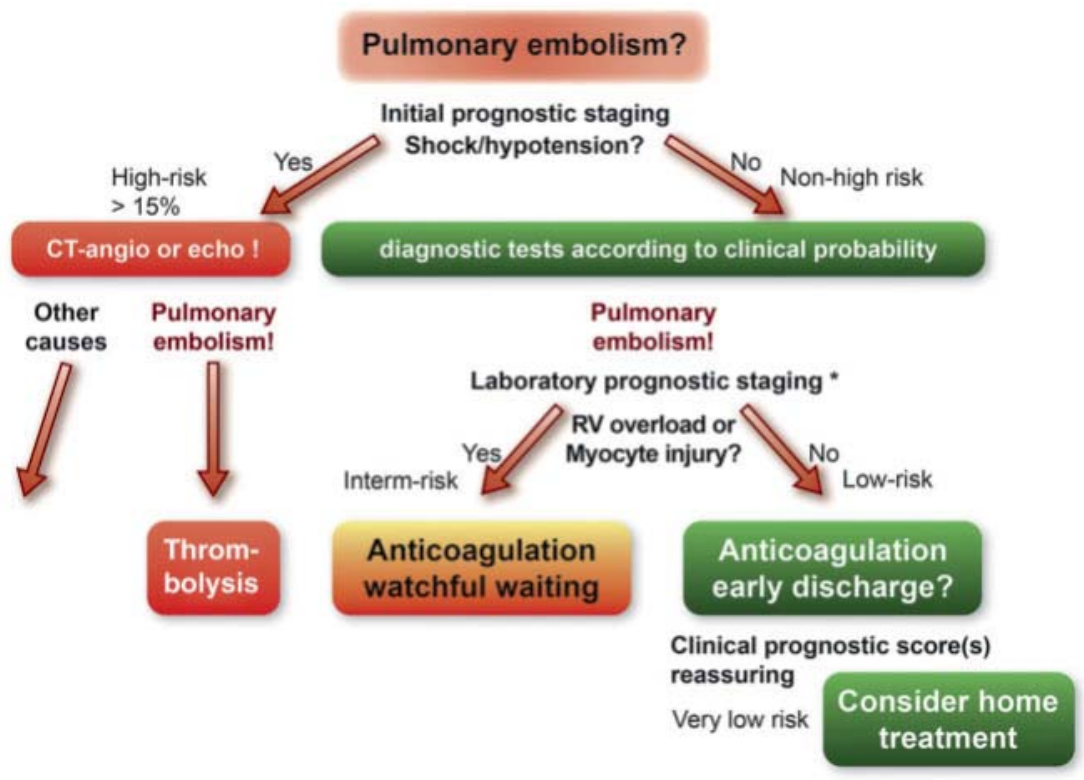

Figure 4. Pulmonary embolism management algorithm. Reproduced with permission from Ref. ${ }^{42}$

I554 patients with atherosclerotic disease in two or three vascular beds (coronary, lower limb, and/or cerebrovascular) showed a significantly larger absolute risk reduction with alirocumab, as compared to patients with isolated coronary artery disease (CAD). The absolute risk reduction regarding MACE was $1.9 \%$ (95\% Cl $-2.4 \%$ to $6.2 \%)$ and $13.0 \%(95 \% \mathrm{Cl}-2.0 \%$ to $28.0 \%$ ) for two and three vascular beds, respectively, whereas regarding all-cause mortality was $1.3 \%(95 \%$ $\mathrm{Cl}-\mathrm{I} .8 \%$ to $4.3 \%)$ and $\mathrm{I} 6.2 \%(95 \% \mathrm{Cl} 5.5-26.8 \%)$, respectively.

Another pillar of themedical treatment of LEAD is optimal control of arterial hypertension., ${ }^{4,33} \mathrm{~A}$ recent analysis fromthe Atherosclerosis Risk in Communities (ARIC) study evaluated the impact of different stages of hypertension on the development of LEAD. ${ }^{34}$ During a median follow-up of 25.4 years, a systolic blood pressure (BP) $\geq 140 \mathrm{mmHg}$ or diastolic BP $\geq 90 \mathrm{mmHg}$ was associated with higher rate of incident LEAD diagnosis (HR 2.40; $95 \% \mathrm{Cl}$ I.72-3.34), independent of the use of anti-hypertensive medications. Higher BP categories showed significant associations with incident LEAD starting from 120 to $129 \mathrm{mmHg}$ for systolic BP and $\geq 90 \mathrm{mmHg}$ for diastolic BP. These data emphasize the need for BP control to prevent the development of LEAD.

While supervised exercise training is a mainstay of the management of claudication, ${ }^{4}$ low adherence rates limit its clinical application. In a randomized study,
I 56 participants were allocated to supervised treadmill exercise, supervised resistance training, or oral advice about nutrition and training. ${ }^{35}$ After 6 months, the 6-min walk distance improved only in the treadmill exercise group $(36.1 \mathrm{~m}, 95 \% \mathrm{Cl}$ I3.9-58.3), but at 12 months neither treadmill nor resistance significantly differed from baseline or control (walking distance: $+7.5 \mathrm{~m}$ and $+6.1 \mathrm{~m}$ ). These results highlight the need for long-term supervised exercise programmes to maintain benefits. Additionally, a systematic review of 84 studies reported that alternative training modalities (circuit exercise, low-pain and pain-free walking, resistance training, upper/lower limb ergometry, and pole striding) had significantly higher adherence and completion rates vs. traditional exercise training $(85.5 \%$ vs. $77.6 \%$, and $86.6 \%$ vs. $80.8 \%$, respectively). ${ }^{36}$

In lack of randomized controlled trials (RCTs), a large gap in evidence regards the best revascularization strategy in chronic limb threatening ischaemia (CLTI). In a retrospective analysis, 16800 patients with CLTI who had first surgical LER (36\%) were compared to those with first endovascular LER (64\%). ${ }^{37}$ The endovascular group was younger, but suffered from more comorbidities, including renal failure $(36 \%$ vs. $24 \%)$, CAD (34\% vs. $32 \%)$, heart failure (19\% vs. $\mathrm{I} 5 \%)$, and diabetes (65\% vs. $58 \%$; all $\mathrm{P}<0.05)$. In a propensitymatched analysis, a surgery-first strategy was associated with worse amputation-free survival (HR I.16, 95\% Cl I.I3-I.20), while an endovascular-first 
strategy was associated with higher reintervention rates (HR I.19, 95\% Cl I.I4-I.23) after 80 months of follow-up. Mortality was similar between groups (HR $0.94,95 \% \mathrm{Cl} 0.89-\mathrm{I} . \mathrm{II})$. These results suggest that an endovascular-first approach might be preferable regarding amputation-free survival.

Several trials have shown the superiority of drugeluting stents (DES) and drug-coated balloons (DCBs) vs. plain balloon angioplasty (PTA) in patients with femoropopliteal disease. ${ }^{1-3}$ The 5 -year results of the IN.PACT SFA trial showed the persistence of clinical benefits, with $74.5 \%$ freedom from clinically driven target lesion revascularization with DCBs vs. $65.3 \%$ with PTA $(P=0.020)$, although this benefit was nonsignificant in diabetics $(70.3$ vs. $64.4 \%, P=0.24) .{ }^{38}$ The clinical use of paclitaxel-eluting devices was dramatically interrupted in November 2018 by the unexpected results of a meta-analysis including $28 \mathrm{RCTs}$ with a total of 4432 patients. ${ }^{39}$ The study described a two-fold increase in all-cause mortality between 2 and 5 years of follow-up with paclitaxel-eluting DES/ DCBs (HR I.93, 95\% Cl I.27-2.93), and a causal link between paclitaxel dose and mortality was hypothesized. These findings raised great concern, halted enrolment in RCTs on paclitaxel-eluting devices, and prompted a worldwide call for high-quality data collection and analysis. Most recently, a confutation of the above-mentioned study came from a large analysis of German health claims data, investigating long-term mortality with paclitaxel-eluting devices from 2007 until present in 64 77I patients undergoing 107 I I 2 endovascular procedures. ${ }^{40}$ The use of paclitaxel-eluting devices was not associated with any signal of increased mortality up to 10 years of follow-up (Figure 3 ).

\section{VENOUS THROMBOEMBOLISM}

In 2019, the ESC issued updated guidelines for management of patients with acute pulmonary embolism (PE). ${ }^{41}$ Key points include use of age-adjusted D-dimer cut-off in preclinical risk assessment. Furthermore, categorization of PE events in 'provoked' and 'unprovoked' is no longer suggested. Rather, occurrence of index event in presence of 'reversible risk factor', or in absence of any 'identifiable risk factor' is suggested for patient stratification and guidance of treatment duration. For the first time, direct oral anticoagulants (DOACs) are recommended over vitamin $\mathrm{K}$ antagonists for PE treatment in eligible patients as for patients with atrial fibrillation. A reduced dose of apixaban or rivaroxaban for extended anticoagulation should be considered after the first 6 months of treatment. Edoxaban or rivaroxaban should be considered as an alternative to low molecular weight heparin in patients with non-gastrointestinal cancer who experience VTE. A new recommendation (class lla, level A) proposes that carefully selected, low-risk PE patients should be considered for early discharge and home treatment, as long as proper outpatient care and anticoagulant therapy are possible (Figure 4). A recent prospective multicentre single-arm trial further corroborates this recommendation. Low-risk PE patients (no HESTIA criteria present, and absence of right ventricle enlargement/dysfunction) were early discharged (maximum of two nights in hospital) for home treatment with rivaroxaban. The study was prematurely terminated because of low symptomatic VTE recurrence and PErelated death rates $(0.6 \%$; onesided upper $99.6 \% \mathrm{Cl}$ $2.1 \%$ ), and low bleeding episodes (1.2\%) at 3 months from diagnosis. ${ }^{43}$ Careful selection of low-risk PE patients is key in successful home treatment; in this regard, clinical severity scores alone may not be sufficient to identify such low-risk group especially with regard to subclinical right ventricular dysfunction exclusion. Therefore, combining right ventricular assessment to clinical criteria further allow proper risk stratification as recently suggested by Barco et al. ${ }^{44}$

The diagnosis of PE during pregnancy is challenging with wide pregnancy-related and PE suspicion symptoms overlap. Overall PE prevalence is however low thus exposing patients to unnecessary imaging tests. The 2019 ESC PE guidelines propose a dedicated diagnostic algorithm for suspected PE in pregnancy using stratification tools based on clinical presentation, DDimer testing, and compression ultrasonography of lower extremities. The pregnancy adapted YEARS algorithm, which takes into account these three parameters, was recently shown to safely rule out $\mathrm{PE}$ across all trimesters of pregnancy avoiding a significant number of imaging tests. ${ }^{45}$

Management of vein thrombosis at unusual sites is challenging in practice. Whether patients with isolated distal deep vein thrombosis (IDDVT) should be systematically treated with anticoagulation is still questioned. It is suggested to stratify patients with IDDVT in high- and low-risk of recurrence. ${ }^{46}$ Those at high risk should be anticoagulated as for proximal deep vein thrombosis. ${ }^{47}$ With this regard, recent prospective registries suggested that patients with IDDVT may be treated with DOACs although data from clinical trials are stillmissing. ${ }^{48,49}$ 


\section{PERSPECTIVES}

Exciting new scientific data published in 2019 shed more light on the nuances of atherosclerosis among the different peripheral vascular territories. The year 2020 is highly awaited for vascular specialists, with the completion of the Vascular Outcomes study of ASA along with rivaroxaban in endovascular or surgical limb revascularization for peripheral artery disease (VOYAGER PAD) study, evaluating the efficacy and safety of rivaroxaban $2.5 \mathrm{mg}$ b.i.d. together with aspirin in reducing the risk of major thrombotic vascular events in subjects with symptomatic LEAD undergoing surgical or endovascular revascularization (NCT02504216). Additionally, further data will become available addressing the safety of paclitaxelcoated technology for LEAD revascularization. In the field of VTE, data from the CARAVAGGIO study (NCT03045406), comparing apixaban to dalteparin, for the treatment of acute VTE in cancer patients, are awaited.

Conflict of interest: C.H. reports research grants from Deutsche Forschungsgemeinschaft, Mitsubishi Cleansui, Wild Blueberry Association of North America, National Processed Raspberry Council, University of Surrey, Philips, Cranberry Institute, Rheacell; personal fees from Bayer, Novo Nordisk, Profil Institute outside the submitted work. J.J.F.B. reports grants and personal fees from Bayer and Rexgenero, personal fees from Amgen, outside the submitted work. M.D.C. reports personal fees from Bayer and Sanofi, outside the submitted work. H.R. reports grants from Bard, Biotronik, Bayer, personal fees from Diaplan, MedUpdate, Daichi Sankyo, and NeoVasc, personal fees and other support from NovoNordisk; other support from Bristol Myers Squibb and Pfizer; grants, personal fees, and other support from Pluristem outside the submitted work and is the senior author of a manuscript which is presented/reviewed in this article. A.P. reports personal fees from Actelion Pharmaceuticals Ltd and from Bristol-Myers Squibb Pharmaceuticals Limited, outside the submitted work. V.A. declares personal fees from Amgen, Bayer, Novartis, NovoNordisk, BMS/Pfizer alliance, and Sanofi, as speaker or advisor. L.M. and I.B. have declared no conflict of interest.

\section{References}

I. De Carlo M, Mazzolai L, Bossone E, Brodmann M, Micari A, Muiesan ML, Ricco JB, Stabile E, Agnelli G, Aboyans V; ESC Working Group on Aorta and Peripheral Vascular Diseases. The year in cardiology 2016: peripheral circulation. Eur Heart J 2017;38:1028-1033.

2. Aboyans V, Vrsalovic M, Madaric J, Mazzolai L, De Carlo M; ESC
Working Group on Aorta and Peripheral Vascular Diseases. The year 2018 in cardiology: aorta and peripheral circulation. Eur Heart 2019;40:872-879.

3. Aboyans V, Braekkan S, Mazzolai L, Sillesen H, Venermo M, De Carlo M; ESC Working Group on Aorta and Peripheral Vascular Diseases. The year 2017 in cardiology: aorta and peripheral circulation. Eur Heart J 2018;39:730-738.

4. Aboyans V, Ricco JB, Bartelink MEL, Bjorck M, Brodmann M, Cohnert T, Collet JP, Czerny M, De Carlo M, Debus S, Espinola-Klein C, Kahan T, Kownator S, Mazzolai L, Naylor AR, Roffi M, Rother J, Sprynger M, Tendera M, Tepe G, Venermo M, Vlachopoulos C, Desormais I; ESC Scientific Document Group. 2017 ESC Guidelines on the Diagnosis and Treatment of Peripheral Arterial Diseases, in collaboration with the European Society for Vascular Surgery (ESVS): document covering atherosclerotic disease of extracranial carotid and vertebral, mesenteric, renal, upper and lower extremity arteries Endorsed by: the European Stroke Organization (ESO)The Task Force for the Diagnosis and Treatment of Peripheral Arterial Diseases of the European Society of Cardiology (ESC) and of the European Society for Vascular Surgery (ESVS). Eur Heart J 20I8;39:763-8I6.

5. Klarin D, Lynch J, Aragam K, Chaffin M, Assimes TL, Huang J, Lee KM, Shao Q, Huffman JE, Natarajan P, Arya S, Small A, Sun YV, Vujkovic M, Freiberg MS, Wang L, Chen J, Saleheen D, Lee JS, Miller DR, Reaven P, Alba PR, Patterson OV, DuVall SL, Boden WE, Beckman JA, Gaziano JM, Concato J, Rader DJ, Cho K, Chang KM, Wilson PWF, O'Donnell C], Kathiresan S; VA Million Veteran Program, Tsao PS, Damrauer SM. Genome-wide association study of peripheral artery disease in the Million Veteran Program. Nat Med 2019;25:I274-1279.

6. Leisegang MS, Bibli SI, Gunther S, Pfluger-Muller B, Oo JA, Hoper C, Seredinski S, Yekelchyk M, Schmitz-Rixen T, Schurmann C, Hu J, Looso M, Sigala F, Boon RA, Fleming I, Brandes RP. Pleiotropic effects of laminar flow and statins depend on the Kruppel-like factorinduced IncRNA MANTIS. Eur Heart J 2019;40:2523-2533.

7. Oppi S, Nusser-Stein S, Blyszczuk P, Wang X, Jomard A, Marzolla V, Yang K, Velagapudi S, Ward LJ, Yuan XM, Geiger MA, Guillaumon AT, Othman A, Hornemann T, Rancic Z, Ryu D, Oosterveer MH, Osto E, Lu"scher TF, Stein S. Macrophage NCORI protects from atherosclerosis by repressing a proatherogenic PPARc signature. Eur Heart J 2019;doi: 10.1093/eurheartj/ehz667.

8. Christersdottir T, Pirault J, Gistera A, Bergman O, Gallina AL, Baumgartner R, Lundberg AM, Eriksson P, Yan ZQ, Paulsson-Berne G, Hansson GK, Olofsson PS, Halle M. Prevention of radiotherapyinduced arterial inflammation by interleukin-I blockade. Eur Heart J 2019;40:2495-2503.

9. Stiekema LCA, Stroes ESG, Verweij SL, Kassahun H, Chen L, Wasserman SM, Sabatine MS, Mani V, Fayad ZA. Persistent arterial wall inflammation in patients with elevated lipoprotein(a) despite strong low-density lipoprotein cholesterol reduction by proprotein convertase subtilisin/kexin type 9 antibody treatment. Eur Heart J 2019;40:2775-278।.

10. Mach F, Baigent C, Catapano AL, Koskinas KC, Casula M, Badimon L, Chapman MJ, De Backer GG, Delgado V, Ference BA, Graham IM, Halliday A, Landmesser U, Mihaylova B, Pedersen TR, Riccardi G, Richter DJ, Sabatine MS, Taskinen MR, Tokgozoglu L, Wiklund O; ESC Scientific Document Group. 2019 ESC/EAS Guidelines for the management of dyslipidaemias: lipid modification to reduce cardiovascular risk. Eur Heart J 2019;doi:10.1093/eurheartj/ehz455.

II. Tzoulaki I, Castagne R, Boulange CL, Karaman I, Chekmeneva E, Evangelou E, Ebbels TMD, Kaluarachchi MR, Chadeau-Hyam M, Mosen D, Dehghan A, Moayyeri A, Ferreira DLS, Guo X, Rotter JI, Taylor KD, Kavousi M, de Vries PS, Lehne B, Loh M, Hofman A, Nicholson JK, Chambers J, Gieger C, Holmes E, Tracy R, Kooner J, Greenland P, Franco OH, Herrington D, Lindon JC, Elliott P. Serum metabolic signatures of coronary and carotid atherosclerosis and subsequent cardiovascular disease. Eur Heart J 2019;40:2883-2896.

12. Fernandez-Friera L, Fuster V, Lopez-Melgar B, Oliva B, SanchezGonzalez J, Macias A, Perez-Asenjo B, Zamudio D, Alonso-Farto JC, Espana S, Mendiguren J, Bueno H, Garcia-Ruiz JM, Ibanez B, Fernan- 
dez-Ortiz A, Sanz J. Vascular inflammation in subclinical atherosclerosis detected by hybrid PET/MRI. J Am Coll Cardiol 2019;73:I37I1382.

13. Senders ML, Hernot S, Carlucci G, van de Voort JC, Fay F, Calcagno C, Tang J, Alaarg A, Zhao Y, Ishino S, Palmisano A, Boeykens G, Meerwaldt AE, Sanchez-Gaytan BL, Baxter S, Zendman L, Lobatto ME, Karakatsanis NA, Robson PM, Broisat A, Raes G, Lewis JS, Tsimikas S, Reiner T, Fayad ZA, Devoogdt N, Mulder WJM, PérezMedina C. Nanobody-facilitated multiparametric PET/MRI phenotyping of atherosclerosis. JACC Cardiovasc Imaging 2019;12:20152026.

14. Charakida M, Georgiopoulos G, Dangardt F, Chiesa ST, Hughes AD, Rapala A, Davey Smith G, Lawlor D, Finer N, Deanfield JE. Early vascular damage from smoking and alcohol in teenage years: the ALSPAC study. Eur Heart J 2019;40:345-353.

15. Mortensen MB, Fuster V, Muntendam P, Mehran R, Baber U, Sartori $S$, Falk E. Negative risk markers for cardiovascular events in the elderly. J Am Coll Cardiol 2019;74:I-II.

16. Naslund $\mathrm{U}, \mathrm{Ng} \mathrm{N}$, Lundgren $\mathrm{A}$, Fharm E, Gronlund $\mathrm{C}$, Johansson $\mathrm{H}$, Lindahl B, Lindahl B, Lindvall K, Nilsson SK, Nordin M, Nordin S, Nyman E, Rocklov J, Vanoli D, Weinehall L, Wennberg P, Wester P, Norberg M; VIPVIZA trial group. Visualization of asymptomatic atherosclerotic disease for optimum cardiovascular prevention (VIPVIZA): a pragmatic, open-label, randomised controlled trial. Lancet 2019;393:133-142.

17. Chiesa ST, Masi S, Shipley MJ, Ellins EA, Fraser AG, Hughes AD, Patel RS, Khir AW, Halcox JP, Singh-Manoux A, Kivimaki M, Celermajer DS, Deanfield JE. Carotid artery wave intensity in mid- to late-life predicts cognitive decline: the Whitehall II study. Eur Heart J 2019;40:2300-2309.

18. Amarenco P, Kim JS, Labreuche J, Charles H, Abtan J, Bejot Y, Cabrejo L, Cha JK, Ducrocq G, Giroud M, Guidoux C, Hobeanu C, Kim YJ, Lapergue B, Lavallee PC, Lee BC, Lee KB, Leys D, Mahagne MH, Meseguer E, Nighoghossian N, Pico F, Samson Y, Sibon I, Steg PG, Sung SM, Touboul PJ, Touze E, Varenne O, Vicaut E, Yelles N, Bruckert E; Treat Stroke to Target Investigators. A comparison of two LDL cholesterol targets after ischemic stroke. $\mathrm{N}$ Engl J Med 2019; doi:10.1056/NEJMoal 910355 [Epub ahead of print].

19. Reddy VY, Neuzil P, de Potter T, van der Heyden J, Tromp SC, Rensing B, Jiresova E, Dujka L, Lekesova V. Permanent percutaneous carotid artery filter to prevent stroke in atrial fibrillation patients: the CAPTURE trial. J Am Coll Cardiol 2019;74:829-839.

20. Nazerian P, Mueller C, Vanni S, Soeiro AM, Leidel BA, Cerini G, Lupia E, Palazzo A, Grifoni S, Morello F. Integration of transthoracic focused cardiac ultrasound in the diagnostic algorithm for suspected acute aortic syndromes. Eur Heart J 2019;40:1952-1960.

21. Erbel R, Aboyans V, Boileau C, Bossone E, Bartolomeo RD, Eggebrecht $\mathrm{H}$, Evangelista A, Falk V, Frank H, Gaemperli O, Grabenwoger M, Haverich A, lung B, Manolis AJ, Meijboom F, Nienaber CA, Roffi M, Rousseau H, Sechtem U, Sirnes PA, Allmen RS, Vrints C); ESC Committee for Practice Guidelines. 2014 ESC Guidelines on the diagnosis and treatment of aortic diseases: Document covering acute and chronic aortic diseases of the thoracic and abdominal aorta of the adult. The Task Force for the Diagnosis and Treatment of Aortic Diseases of the European Society of Cardiology (ESC). Eur Heart J 2014;35:2873-2926.

22. Ahn JM, Kim H, Kwon O, Om SY, Heo R, Lee S, Kim DH, Kim $\mathrm{HJ}$, Kim JB, Jung SH, Choo SJ, Song JM, Kang DH, Chung CH, Lee JW, Song JK. Differential clinical features and long-term prognosis of acute aortic syndrome according to disease entity. Eur Heart J 2019;40:2727-2736

23. Guala A, Teixidó-Tura G, Rodríguez-Palomares J, Ruiz-Munoz A, Dux-Santoy L, Villalva N, Granato C, Galian L, Gutiérrez L, GonzálezAlujas T, Sanchez V, Forteza A, García-Dorado D, Evangelista A. Proximal aorta longitudinal strain predicts aortic root dilation rate and aortic events in Marfan syndrome. Eur Heart J 2019;40:20472055.

24. Desai D, Miranda W, Connolly H, Tajik AJ. Flow dynamics in the false lumen in distal aorta following surgery for type $A$ aortic dissection. Eur Heart J 2019;40:56I-56I.
The year in cardiology 20 19: aorta and peripheral circulation

25. Chiu P, Goldstone AB, Schaffer JM, Lingala B, Miller DC, Mitchell RS, Woo YJ, Fischbein MP, Dake MD. Endovascular versus open repair of intact descending thoracic aortic aneurysms. J Am Coll Cardiol 2019;73:643-65।.

26. Lederle FA, Kyriakides TC, Stroupe KT, Freischlag JA, Padberg FT, Jr., Matsumura JS, Huo Z, Johnson GR; OVER Veterans Affairs Cooperative Study Group. Open versus endovascular repair of abdominal aortic aneurysm. N Engl J Med 2019;380:2 | 26-2/35.

27. Song P, Rudan D, Zhu Y, Fowkes FJI, Rahimi K, Fowkes FGR, Rudan I. Global, regional, and national prevalence and risk factors for peripheral artery disease in 2015: an updated systematic review and analysis. Lancet Glob Health 2019;7:e 1020-el030.

28. Beckman JA, Duncan MS, Damrauer SM, Wells QS, Barnett JV, Wasserman DH, Bedimo RJ, Butt AA, Marconi VC, Sico JJ, Tindle HA, Bonaca MP, Aday AW, Freiberg MS. Microvascular disease, peripheral artery disease, and amputation. Circulation 2019;140:449-458.

29. Hess CN, Huang Z, Patel MR, Baumgartner I, Berger JS, Blomster JI, Fowkes FGR, Held P, Jones WS, Katona B, Mahaffey KW, Norgren L, Rockhold FW, Hiatt WR. Acute limb ischemia in peripheral artery disease. Circulation 2019;140:556-565.

30. Baumgartner I, Norgren L, Fowkes FGR, Mulder H, Patel MR, Berger JS, Jones WS, Rockhold FW, Katona BG, Mahaffey K, Hiatt WR; Executive Committee and Investigators of the EUCLID Trial. Cardiovascular outcomes after lower extremity endovascular or surgical revascularization: the EUCLID trial. J Am Coll Cardiol 2018;72:1563-1572.

31. Navi BB, Reiner AS, Kamel H, ladecola C, Okin PM, Tagawa ST, Panageas KS, DeAngelis LM. Arterial thromboembolic events preceding the diagnosis of cancer in older persons. Blood 2019;133:78I-789.

32. Jukema JW, Szarek M, Zijlstra LE, de Silva HA, Bhatt DL, Bittner VA, Diaz R, Edelberg JM, Goodman SG, Hanotin C, Harrington RA, Karpov Y, Moryusef A, Pordy R, Prieto JC, Roe MT, White HD, Zeiher AM, Schwartz GG, Steg PG; ODYSSEY OUTCOMES Committees and Investigators. Alirocumab in patients with polyvascular disease and recent acute coronary syndrome: ODYSSEY OUTCOMES trial. J Am Coll Cardiol 2019;74: I 167-I I76.

33. Williams B, Mancia G, Spiering W, Agabiti Rosei E, Azizi M, Burnier M, Clement DL, Coca A, de Simone G, Dominiczak A, Kahan T, Mahfoud F, Redon J, Ruilope L, Zanchetti A, Kerins M, Kjeldsen SE, Kreutz R, Laurent S, Lip GYH, McManus R, Narkiewicz K, Ruschitzka F, Schmieder RE, Shlyakhto E, Tsioufis C, Aboyans V, Desormais I; ESC Scientific Document Group. 2018 ESC/ESH Guidelines for the management of arterial hypertension. Eur Heart J 2018;39:302 I3104.

34. Lu Y, Ballew SH, Tanaka H, Szklo M, Heiss G, Coresh J, Matsushita K. 2017 ACC/AHA blood pressure classification and incident peripheral artery disease: the Atherosclerosis Risk in Communities (ARIC) study. Eur J Prev Cardiol 2019; doi:10.1 177/20474873/9865378 [Epub ahead of print].

35. McDermott MM, Kibbe MR, Guralnik JM, Ferrucci L, Criqui MH, Domanchuk K, Tian L, Zhao L, Li L, Patel K, Polonsky TS. Durability of benefits from supervised treadmill exercise in people with peripheral artery disease. J Am Heart Assoc 2019;8:e009380.

36. Lin E, Nguyen $\mathrm{CH}$, Thomas SG. Completion and adherence rates to exercise interventions in intermittent claudication: traditional exercise versus alternative exercise-a systematic review. Eur J Prev Cardiol 2019;26:1625-1633.

37. Lin JH, Brunson A, Romano PS, Mell MW, Humphries MD. Endovascular-first treatment is associated with improved amputation-free survival in patients with critical limb ischemia. Circ Cardiovasc Qual Outcomes 2019;12:e005273.

38. Laird JA, Schneider PA, Jaff MR, Brodmann M, Zeller T, Metzger DC, Krishnan P, Scheinert D, Micari A, Wang H, Masters M, Tepe G. Long-term clinical effectiveness of a drug-coated balloon for the treatment of femoropopliteal lesions. Circ Cardiovasc Interv 2019;12:e007702.

39. Katsanos K, Spiliopoulos S, Kitrou P, Krokidis M, Karnabatidis D. Risk of death following application of paclitaxel-coated balloons and stents in the femoropopliteal artery of the leg: a systematic review 
and meta-analysis of randomized controlled trials. J Am Heart Assoc 2018;7:e0 I I245.

40. Freisinger E, Koeppe J, Gerss J, Goerlich D, Malyar N, Marschall U, Faldum A, Reinecke H. Mortality after use of paclitaxel-based devices in peripheral arteries: a real-world safety analysis. Eur Heart J 2019;doi:10.1093/eurheartj/ehz698.

4I. Konstantinides SV, Meyer G, Becattini C, Bueno H, Geersing G], Harjola VP, Huisman MV, Humbert $M$, Jennings $C S$, Jiménez $D$, Kucher N, Lang IM, Lankeit M, Lorusso R, Mazzolai L, Meneveau N, Ní Á inle F, Prandoni P, Pruszczyk P, Righini M, Torbicki A, Van Belle E, Zamorano JL; ESC Scientific Document Group. 2019 ESC Guidelines for the diagnosis and management of acute pulmonary embolism developed in collaboration with the European Respiratory Society (ERS). Eur Heart J 2019;doi: 10.1093/eurheartj/ehz405.

42. Torbicki A. Assessing the severity of acute pulmonary embolism: back to the future? Eur Heart J 2019;40:91 I-913.

43. Barco S, Schmidtmann I, Ageno W, Bauersachs RM, Becattini C, Bernardi E, Beyer-Westendorf J, Bonacchini L, Brachmann J, Christ M, Czihal M, Duerschmied D, Empen K, Espinola-Klein C, Ficker JH, Fonseca C, Genth-Zotz S, Jimenez D, Harjola VP, Held M, logna Prat L, Lange TJ, Manolis A, Meyer A, Mustonen P, Rauch-Kroehnert U, Ruiz-Artacho P, Schellong S, Schwaiblmair M, Stahrenberg R, Westerweel PE, Wild PS, Konstantinides SV, Lankeit M; on behalf of the HoT-PE Investigators. Early discharge and home treatment of patients with low-risk pulmonary embolism with the oral factor $\mathrm{Xa}$ inhibitor rivaroxaban: an international multicentre single-arm clinical trial. Eur Heart J 2019;doi: I0.1093/eurheartj/ehz367.

44. Barco S, Mahmoudpour SH, Planquette B, Sanchez O, Konstantinides SV, Meyer G. Prognostic value of right ventricular dysfunction or elevated cardiac biomarkers in patients with low-risk pulmonary embolism: a systematic review and meta-analysis. Eur Heart J 2019;40:902-910.
45. van der Pol LM, Tromeur C, Bistervels IM, Ni Ainle F, van Bemmel T, Bertoletti L, Couturaud F, van Dooren YPA, Elias A, Faber LM, Hofstee HMA, van der Hulle T, Kruip M, Maignan M, Mairuhu ATA Middeldorp S, Nijkeuter M, Roy PM, Sanchez O, Schmidt J, Ten Wolde M, Klok FA, Huisman MV, Artemis SI. Pregnancy-adapted YEARS algorithm for diagnosis of suspected pulmonary embolism. $\mathrm{N}$ Engl J Med 2019;380: I 139-1149.

46. Valerio L, Ambaglio C, Barone M, Ciola M, Konstantinides SV, Mahmoudpour SH, Picchi C, Pieresca C, Trinchero A, Barco S. Recurrence risk after first symptomatic distal versus proximal deep vein thrombosis according to baseline risk factors. TH Open 2019;3:e58e63.

47. Mazzolai L, Aboyans V, Ageno W, Agnelli G, Alatri A, Bauersachs R, Brekelmans MPA, Buller HR, Elias A, Farge D, Konstantinides S, Palareti G, Prandoni P, Righini M, Torbicki A, Vlachopoulos C, Brodmann $M$. Diagnosis and management of acute deep vein thrombosis: a joint consensus document from the European Society of Cardiology working groups of aorta and peripheral vascular diseases and pulmonary circulation and right ventricular function. Eur Heart J 2018;39:4208-4218.

48. Ageno W, Mantovani LG, Haas S, Kreutz R, Monje D, Schneider J, Bugge JP, Gebel M, Turpie A. Patient management strategies and long-term outcomes in isolated distal deep-vein thrombosis versus proximal deep-vein thrombosis: findings from XALIA. TH Open 2019;3:e85-e93.

49. Schellong SM, Goldhaber SZ, Weitz JI, Ageno W, Bounameaux H, Turpie AGG, Angchaisuksiri P, Haas S, Goto S, Zaghdoun A, Farjat A, Nielsen JD, Kayani G, Mantovani LG, Prandoni P, Kakkar AK. Isolated distal deep vein thrombosis: perspectives from the GARFIELDVTE registry. Thromb Haemost 2019;19:1675-1685. 